\title{
Early onset cerebellar ataxia with retained tendon reflexes: a clinical and genetic study of a disorder distinct from Friedreich's ataxia
}

\author{
A E H A R D I N G* \\ From the MRC Clinical Genetics Unit, Institute of Child Health, London
}

S U M MARY Twenty patients are described with a distinctive clinical syndrome characterised by progressive cerebellar ataxia developing within the first two decades. This is associated with dysarthria, pyramidal signs in the limbs, normal or increased knee jerks and upper limb reflexes and in some instances sensory loss. Inheritance is probably autosomal recessive in the majority, if not all, of the cases. The preservation of tendon reflexes distinguishes this disorder from Friedreich's ataxia. Other important differences from Friedreich's ataxia are absence of optic atrophy, cardiomyopathy, diabetes mellitus and severe skeletal deformity. The prognosis was better in the present series than in cases of Friedreich's ataxia; patients remained ambulant, on average, for more than 10 years longer.

Nicolaus Friedreich first reported the disorder which now bears his name in $1863 .^{1} \mathrm{He}$ described a distinctive clinical syndrome in nine members of three sibships in a series of five papers between 1863 and $1877^{1-5}$ The age of onset of the disorder was around puberty. Ataxia and dysarthria were prominent; sensory loss and muscle weakness were later findings. Friedreich did not comment on the loss of tendon reflexes in his cases until his later papers as these reflexes were not described until $1875 .{ }^{6}$ Ladame, $^{7}$ in a review of 165 published cases, felt that the presence of knee and ankle jerks excluded a diagnosis of Friedreich's ataxia (FA), but Wilson, ${ }^{8}$ on the basis of his own cases, found this view untenable. Nevertheless Tyrer ${ }^{9}$ stated that "many neurologists would at least hesitate to diagnose FA clinically in the presence of exaggerated deep reflexes". Universal absence of tendon reflexes in the lower limbs in FA has been confirmed by other authors ${ }^{10^{-12}}$ in recent years.

In 1934, Sherman ${ }^{13}$ described two patients in whom the clinical features were very similar to

\footnotetext{
* Present address: Department of Neurology, The Middlesex Hospital, Mortimer Street, London W1.

Address for reprint requests: Dr AE Harding, Dept of Neurology, The Middlesex Hospital, Mortimer St, London W1N 8AA.

Accepted 31 March 1981
}

those of FA but the tendon reflexes were increased. Sherman commented: "this report offers some corroboration of the contention that a spastic form of Friedreich's disease exists." Such cases have rarely been described before or since, and most have been labelled as examples of FA. This paper describes the clinical and genetic features of 20 families in which affected individuals had a progressive cerebellar ataxia, developing within the first two decades, associated with dysarthria, pyramidal weakness of the limbs and retained or increased upper limb reflexes and knee jerks. This disorder is clinically distinct from Friedreich's ataxia and there are other important differences between the two disorders.

\section{Patients and methods}

The patients were seen during a clinical and genetic study of 200 families with progressive cerebellar and spinocerebellar degenerations. The families contained 234 index cases which were ascertained from the medical records departments of The Hospital for Sick Children, Great Ormond Street, The National Hospital for Nervous Diseases, other London neurological centres and the records of the Friedreich's Ataxia Group. Patients were included in the study if they had attended hospital during the period 19661980 , and lived within a 50 mile radius of central London. Co-operative individuals were visited at home or in hospital by the author. A detailed history 
was taken which included details of first and second degree relatives. Full neurological and general examinations, twelve lead electrocardiography and urine testing were performed on the index cases. As many first degree relatives were seen and examined as possible.

The cases were initially divided into six major categories for the purpose of further analysis. These were as follows: Friedreich's ataxia (as defined clinically by Tyrer, ${ }^{9}$ Geoffroy $e t a l^{14}$ and other workers; 90 families); progressive ataxia developing within the first two decades associated with dysarthria and generally normal or increased tendon reflexes (20 families); hereditary spastic paraplegia (29 families); late onset cerebellar ataxia of autosomal dominant inheritance (11 families); single cases of late onset cerebellar ataxia (36 families); and other syndromes. The patients reported here are those of the second category.

\section{Results}

The 20 families contained 21 index cases, of which
20 were personally seen. Eleven were male and nine female. The mean age at the time of the study was $41 \cdot 85 \pm 14.95$ years; the mean duration of the disorder was $32 \cdot 3 \pm 16 \cdot 81$ years.

\section{Genetic aspects}

Four patients gave a history of a similar disorder in five siblings. None had affected parents or children. Four parents and three children were examined and found to be normal. The rest were dead or unavailable for study. Only three patients over the age of 25 had reproduced; they had had six children. A total of 55 sibs were stated to be normal; two of these were examined personally. Three patients (two British and one Indian) had parents who were first cousins, so the consanguinity rate in this disorder was $15 \%$ Segregation analysis was performed on these families, using Weinberg's proband method with correction for family size. ${ }^{15}$ The segregation ratio was $0 \cdot 146$, and its $95 \%$ confidence limits were

Table 1 Early onset cerebellar ataxia: clinical features

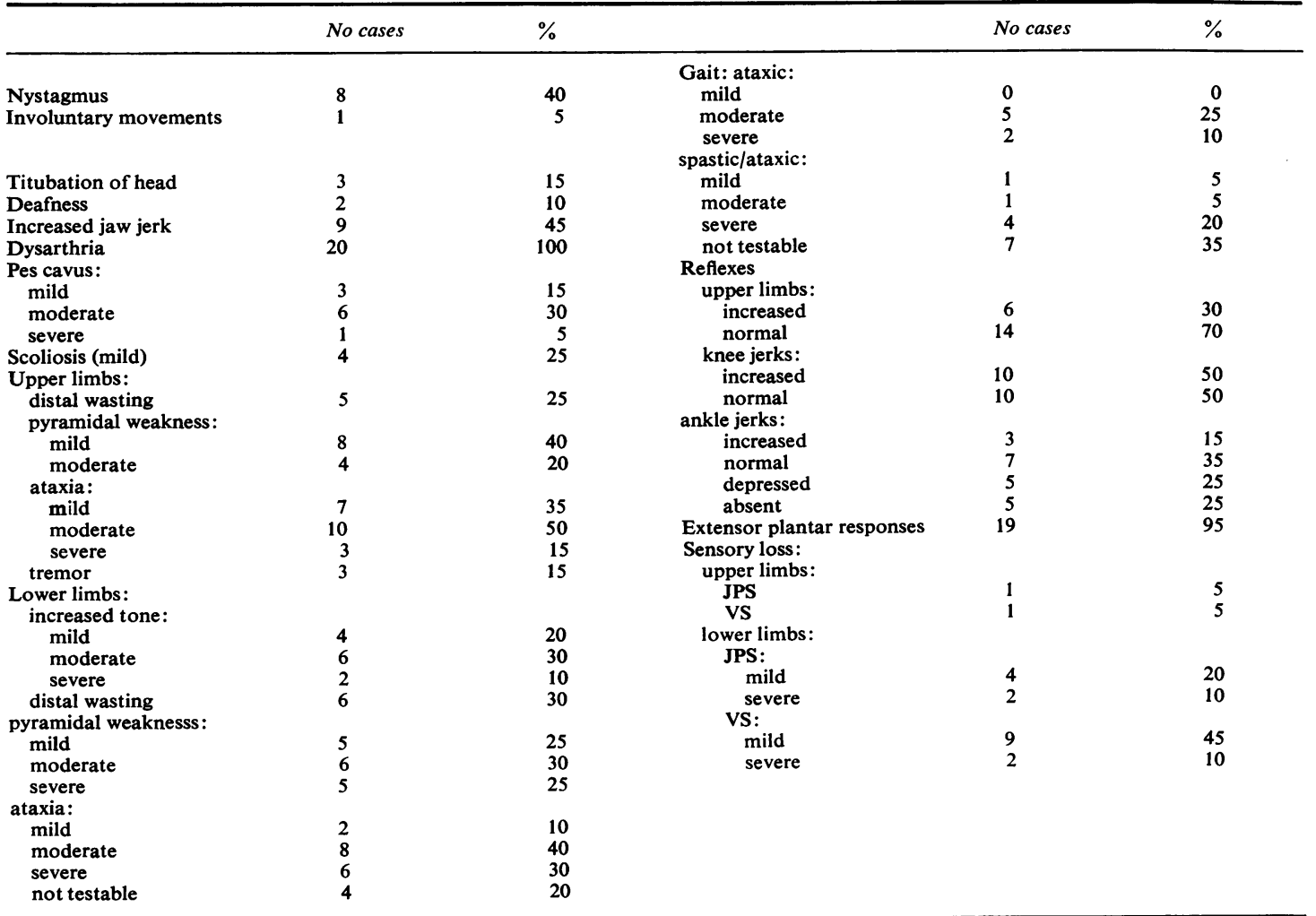

JPS and VS $=$ joint position and vibration sense 
$0 \cdot 027-0.265$. The segregation ratio was not significantly different from $0 \cdot 25(t=1 \cdot 72, \mathrm{p}>0 \cdot 05)$.

\section{Clinical features}

The mean age of onset was $9 \cdot 42 \pm 5.23$ years (range: 18 months-20 years). Ataxia of gait was the most frequent initial symptom (12 patients); a tendency to trip (4), clumsiness (3) and tremor (1) were others. The clinical picture in all cases was of an unremitting, progressive ataxia of gait, with increasing ataxia in the upper limbs. Spasticity in the legs was usually prominent; the arms were similarly affected late in the course of the disease.

The incidence of various clinical features is shown in Table 1. Dysarthria was mild or moderate in most patients; it was cerebellar in type in 19 cases and a combination of cerebellar and spastic in one. One patient had dysphagia (after a protracted course) and one intermittent inspiratory stridor. Tongue movements were slow and spastic in 12; wasting was absent. In nine cases, the jaw jerk was increased. Nystagmus on lateral gaze occurred in nearly half and was present on vertical gaze in one quarter. Two had jerky pursuit eye movements. Sensorineural deafness was present in two patients, both of whom had affected sibs; one of these was also deaf. Two patients had sub-normal intelligence but there was no evidence of progressive deterioration in either. One of these had some involuntary movements of the face. Three cases had titubation of the head. Pyramidal weakness in the arms was present in 12 patients but was usually mild. Reflexes in the upper limbs were normal or increased in all individuals. Six cases demonstrated mild or moderate wasting of the small hand muscles. Cerebellar ataxia in the upper limbs, usually of moderate degree, occurred in all the patients; three additionally had tremor of the outstretched hands. Pyramidal signs were more marked in the lower limbs, with increased tone in $60 \%$; weakness was noted in nearly all cases and was severe in five. The knee jerks were increased in half. In 10 patients, however, the ankle jerks were depressed or absent. The plantar responses were extensor in every case except one, a boy aged 17 who was the youngest patient studied. Cerebellar ataxia was present in the lower limbs in all individuals in which it was testable. Seven patients were totally unable to walk; the gait was ataxic or spastic-ataxic in the remainder. Sensory loss in the lower limbs occurred in 11 patients. Vibration sense was more commonly affected than joint position sense; pain and touch appreciation were normal. Only one individual had sensory loss in the upper limbs. Three patients had urinary symptoms, one frequency, one urgency and the other incontinence. Skeletal deformity was relatively frequent. Half of the cases had pes cavus and $20 \%$ had scoliosis. None of the patients had optic atrophy, retinal degeneration, ophthalmoplegia or hypogonadism. Twelve patients were wheelchair-bound (five of these could walk a few steps with considerable assistance). The mean age of becoming chairbound was $38 \cdot 17 \pm 13.43$ years (range 21-64) and the mean course of the disease (age chairbound minus age of onset) was 32.67士 $19 \cdot 42$ years (range $13-60$ ).

\section{Other features}

Electrocardiographs were recorded in all of the patients. Thirteen were normal. Three patients (of whom none was hypertensive) had left ventricular hypertrophy on voltage criteria; one ECG showed clockwise rotation. Two cases had significant left axis deviation, and one had right axis deviation. None of the ECGs showed abnormal T-wave changes.

\section{Investigations}

Six patients had had nerve conduction studies performed on the median, peroneal and sural nerves; these were normal in four instances. In two, sensory action potentials were reduced in size but motor conduction velocity was normal. One of these had absent ankle jerks and mild reduction of joint position and vibration sense in the toes but the other had normal proprioception and tendon reflexes.

The results of CT scans were available in nine cases; four of these were normal. The remainder showed cerebellar atrophy.

\section{Comparison with Friedreich's ataxia}

Nine of these 20 patients had been diagnosed as suffering from Friedreich's ataxia at some stage of their disease. For this reason their clinical features were compared with those of a series of 115 patients with FA. ${ }^{15^{\mathrm{a}}}$ The mean age at the time of study $(22.0 \pm 12.76$ years) was less than that of the non-Friedreich group $(t=2 \cdot 82, \mathrm{p}<0.01)$. The mean ages of onset in the two disorders were not significantly different $(10.52 \pm 7 \cdot 4$ years in FA; $t=$ $0 \cdot 892, \mathrm{p}<0 \cdot 1)$. However, both the mean age of becoming wheelchair-bound, and the mean number of years that patients were ambulant after onset were less in Friedreich's ataxia $(25 \cdot 14 \pm 15.5$ and $15 \cdot 51 \pm 7 \cdot 41$ years for FA respectively; age wheel- 
chair-bound: $t=4.06, \mathrm{p}<0.001$; "course": $t=5.87$, $\mathrm{p}<0.001$ ).

Table 2 shows the incidence of various clinical features in the two disorders. This does not include reflex changes as they were included in the diagnostic criteria for both groups of patients. Apart from the presence of normal or increased knee jerks and upper limb reflexes, the statistically significant differences which distinguish the present group of cases from those with FA were: less severe ataxia in the upper limbs, less reduction of joint position sense, absence of optic atrophy and considerably fewer patients with scoliosis. Spinal deformity was only mild in the four cases in whom it was present, which is in considerable contrast to the situation in FA.

Table 2 Early onset cerebellar ataxia (EOCA) versus Friedreich's ataxia

\begin{tabular}{|c|c|c|c|}
\hline \multirow[t]{2}{*}{ Clinical features } & \multicolumn{3}{|c|}{ Number of cases } \\
\hline & $\begin{array}{l}E O C A \\
(20)\end{array}$ & $\begin{array}{l}F A \\
(I 15)\end{array}$ & $p$ \\
\hline Nystagmus & 8 & 23 & NS \\
\hline Deafness & 2 & 9 & NS \\
\hline Optic atrophy & 0 & 35 & $<0.01$ \\
\hline Titubation of head & 3 & 5 & NS \\
\hline \multicolumn{4}{|l|}{ Upper limbs: } \\
\hline distal wasting & 5 & 56 & NS \\
\hline pyramidal weakness & 12 & 72 & NS \\
\hline finger-nose ataxia & 20 & 115 & NS \\
\hline dysdiadochokinesis & 19 & 111 & NS \\
\hline severe finger-nose ataxia & 3 & 46 & $<0.01$ \\
\hline \multicolumn{4}{|l|}{ Lower limbs: } \\
\hline pyramidal weakness & 16 & 101 & NS \\
\hline heel-shin ataxia & 20 & 115 & \\
\hline dysdiadochokinesis & 20 & 115 & \\
\hline Extensor plantar responses & 19 & 102 & NS \\
\hline Scoliosis & 4 & 91 & $<0.001$ \\
\hline Pes cavus & 10 & 63 & NS \\
\hline \multicolumn{4}{|c|}{ Sensory loss: upper limbs } \\
\hline VS & 1 & 15 & NS \\
\hline JPS & 1 & 27 & NS \\
\hline lower limbs & & & \\
\hline VS & 11 & 84 & NS \\
\hline JPS & 6 & 90 & $<0.001$ \\
\hline
\end{tabular}

(Comparison by Yates' $\chi^{2}$ test)

In addition to these neurological features, none of the patients with early onset cerebellar ataxia had ECG changes consistent with cardiomyopathy, whereas these occurred in nearly $70 \%$ of cases of FA. Also, there did not appear to be an increased incidence of diabetes; this was present in about $10 \%$ of the FA patients.

\section{Discussion}

The clinical syndrome represented by the 20 cases in this series has rarely been described before. The probable explanation is that such patients are likely to be diagnosed as FA as were nearly half of the patients reported here. Superficially these patients do resemble those with FA. Nevertheless there are important differences between the two disorders. The preservation and in many cases exaggeration of tendon reflexes (except the ankle jerk) in early onset cerebellar ataxia points to a different pathophysiology from that of FA where there is always degeneration of the dorsal root ganglion cells, dorsal roots and large myelinated afferent fibres in the peripheral nerves ${ }^{16}$ leading to interruption of the afferent part of the reflex arc. Other major distinguishing features are the absence of cardiomyopathy, optic atrophy and severe scoliosis in early onset cerebellar ataxia. The prognosis is also better than in FA; the patients in this series, on average, became wheelchair-bound over 10 years later than cases of FA. Loss of joint position sense is also less frequent in this disorder, and ataxia less severe in the upper limbs. The incidence of dysarthria, deafness, pes cavus, nystagmus, pyramidal weakness and extensor plantar responses is similar. Although nerve conduction studies were performed in only six patients with early onset cerebellar ataxia, none had absent sensory action potentials; these findings are quite different from those in $\mathbf{F A}^{17}$ in which such potentials are virtually always absent using conventional percutaneous recording techniques.

One criticism that could be made of the distinction of these patients from those with FA mainly on the basis of reflex changes is that unfortunately it was only possible to examine one affected individual from each family studied. If the other affected sibs had been found to have areflexia, this distinction would clearly be suspect. Nevertheless, this possibility is considered to be unlikely. There is only one family described in the literature where two patients with classical FA had an affected (younger) sib with brisk tendon reflexes. ${ }^{13}$ It is also of importance that none of the affected sibs of index cases with Friedreich's ataxia seen by the author had normal or increased tendon reflexes. Furthermore, other clinical differences between these two disorders are evident which make their separation rational.

The high rate of consanguinity amongst the parents of these patients is suggestive of autosomal recessive inheritance. The segregation ratio obtained $(0 \cdot 146)$ is relatively low, but it is not different from an expected value for autosomal recessive inheritance of $\mathbf{0 \cdot 2 5}$. If some of the cases were not autosomal recessive, the only other explanations for their occurrence would be the presence of non-genetic phenocopies, new 
dominant mutations or some males with X-linked recessive inheritance. The first seems unlikely. In relation to the second possibility, although the number of children of these patients was small, none was affected. Clinically, the present series was not similar to previously described cases of autosomal dominant cerebellar ataxia; ${ }^{18}$ in particular, the high incidence of ophthalmoplegia, optic atrophy and extrapyramidal features found in dominant cases was not evident in those with early onset cerebellar ataxia. The age of onset in the former is also usually in the third or fourth decades. ${ }^{18}$ It is of course possible that some of these cases might represent new mutations of a different dominant disorder. To the author's knowledge, no such dominant pedigrees have been reported and, if this were the explanation, biological fitness would presumably be impaired. As just stated, few patients in the current series had reproduced.

In relation to the possibility of $\mathrm{X}$-linked recessive inheritance, it is of interest that the present patients are clinically quite similar to the $\mathrm{X}$-linked cases described by Shokeir ${ }^{19}$ and Spira et al. ${ }^{20}$ However, none of the male cases reported here had a family history suggestive of X-linked recessive inheritance. Furthermore, the sex ratio of affected males to females (11:9) was close to unity. There were no affected sib pairs in which the disorder was confined to males. There were eight families in which a single male was affected, which could theoretically be the result of X-linked inheritance (excluding one with consanguineous parents). If some of these were X-linked and all had maternal grandmothers who were carriers, there were a total of 27 males who might be at risk of being affected; all were normal. It thus appears that a major contribution to this series by $\mathrm{X}$-linked cases is unlikely. The available evidence suggests that the majority, if not all of these cases, are of autosomal recessive inheritance.

As has been mentioned, previous reports of this disorder are scarce. The cases of Fraser ${ }^{21}$ and Nonne, ${ }^{22}$ both of which were included in Marie's ${ }^{23}$ description of hereditary cerebellar ataxia, were similar, but there was evidence of optic atrophy in both families. Many of the reported cases of early onset cerebellar ataxia in the literature have had associated optic atrophy, moderate to severe mental retardation or dementia, ${ }^{24} 25$ none of which features were present in the current series. Hodge, ${ }^{26}$ under the title of "three cases of Friedreich's disease, all presenting marked increase of the knee jerk" described three sibs with a progressive cerebellar ataxia develop- ing around puberty; none was able to walk unsupported by the age of 40 years and all had increased tendon reflexes. This family was thus similar to the cases reported here. Two of Hodge's patients had moderate wasting of the small hand muscles, which was observed in some cases in the present series. Other families which appear to be similar have been described by Burgess, ${ }^{27}$ Soderburgh, ${ }^{28}$ Sinkler, ${ }^{29}$ Harris $^{30}$ and Sherman. ${ }^{13}$ It is of interest that a few of these patients were noted to have involuntary movements of the face, which were seen in one individual in this study. Fickler ${ }^{31}$ reported cerebellar ataxia, dysarthria, titubation of the head and normal tendon reflexes which developed before the age of 20 in two sibs. Necropsy in one case showed olivopontocerebellar atrophy; the spinal cord was normal albeit "small." Konigsmark and Weiner ${ }^{18}$ included this family in their classification of the olivopontocerebellar atrophies (OPCA) as an example of OPCA type II; they stated that this type was characterised by normal sensation and lack of involuntary movements. This statement was based on two families; no clinical details were known about the other. ${ }^{32}$ The family of Fickler is certainly similar to those in this study.

There have been no recent reports of such cases. The autosomal recessive spastic ataxia of Charlevoix-Saguenay ${ }^{33}$ is clearly different because of the prominent amyotrophy and more marked spasticity. This disorder is more akin to the Troyer syndrome $^{34}$ than the one described here.

Apart from the description of Fickler ${ }^{31}$ there have been no necropsy findings recorded in this disease. The presence of OPCA in Fickler's case is of interest, as there is some evidence that there may be more pathology in the brain in early onset cerebellar ataxia than in FA. CT scans in five out of nine patients in the present series showed cerebellar atrophy; this is rare in FA. ${ }^{35}$ Nevertheless, it is unlikely that there are no pathological changes in the spinal cord, given the relatively high incidence of sensory loss, and in some cases loss of the ankle jerks. Further neurophysiological investigations, including both nerve conduction studies and spinal evoked responses are required to elucidate the pathogenesis of this disorder.

I thank the following who kindly allowed me to study their patients: Professors RW Gilliatt, J Marshall, J Newsom-Davis, Sir Roger Bannister, and Drs CJ Earl, PC Gautier-Smith, PKP Harvey, RAC Hughes, $R$ Kelly and $R$ Ross-Russell. Financial support from the Friedreich's Ataxia 
Group and the Medical Research Council is gratefully acknowledged.

\section{References}

1 Friedreich N. Uber degenerative Atrophie der spinalen Hinterstränge. Virchows Arch (Pathol Anat) 1863; 26:391-419.

2 Friedreich $\mathrm{N}$. Uber degenerative Atrophie der spinalen Hinterstränge. Virchows Arch (Pathol Anat) 1863; 26:433-59.

3 Friedreich $\mathrm{N}$. Uber degenerative Atrophie der spinalen Hinterstränge. Virchows Arch (Pathol Anat) 1863; 27:1-26.

4 Friedreich $\mathrm{N}$. Uber ataxie mit besonderer berücksichtigung der hereditären formen. Virchows Arch (Pathol Anat) 1876; 68:145-245.

5 Friedreich N. Uber ataxie mit besonderer berücksichtigung der hereditären formen. Virchows Arch (Pathol Anat) 1877; 70:140-52.

6 Erb WH. Uber Sehnenreflexe bei Gesunden und bei Rückenmarkskranken. Arch Psychiat Nervenkr 1875; 5:792-802.

7 Ladame P. Friedreich's disease. Brain 1890; 13: 467-537.

8 Wilson SAK. In Bruce AN, ed. Neurology. London: Arnold, 1940.

9 Tyrer JH. Friedreich's ataxia. In Vinken PJ, Bruyn GW, eds. Handbook of Clinical Neurology. Amsterdam: North Holland Publishing Company, Vol 21, 1975; 319-64.

10 Dyck PJ, Lambert EH. Lower motor and primary sensory neuron diseases with peroneal muscular atrophy. II Neurologic, genetic and electrophysiologic findings in various neuronal degenerations. Arch Neurol 1968; 18:619-25.

11 Salisachs P. La historia natural de la enfermedad de Friedreich. A proposito de 13 casos. Med Clinica 1974; 63:1-10.

12 Tyrer JH, Sutherland JM. The primary spinocerebellar atrophies and their associated defects, with a study of the foot deformity. Brain 1961; 84:289-300.

13 Sherman I. Friedreich's disease. A report of two unusual cases. Arch Neurol 1934; 32:1282-5.

14 Geoffroy G, Barbeau A, Breton A, Lemieux B, Aube M, Leger C, Bouchard JB. Clinical description and roentgenologic evaluation of patients with Friedreich's ataxia. Canad J Neurol Sci 1976; 3:279-86.

15 Crow JF. Problems of ascertainment in the analysis of family data. In: Neel JV, Shaw MW, Schull WJ, eds. Genetics and the Epidemiology of Chronic Diseases. Public Health Service Publication No 1163, Washington, 1963; 23-44.

15a Harding AE. Friedreich's ataxia. A clinical and genetic study of 90 families with an analysis of early diagnostic criteria and intrafamily clustering of clinical features. Brain (in press).
16 Hughes JT, Brownell B, Hewer RL. The peripheral sensory pathway in Friedreich's ataxia. Brain 1968; 91:803-18.

17 McLeod JG. An electrophysiological and pathological study of peripheral nerves in Friedreich's ataxia. J Neurol Sci 1971; 12:333-49.

18 Konigsmark BW, Weiner LP. The olivopontocerebellar atrophies: a review. Medicine 1970; 49:227-41.

19 Shokeir MHK. X-linked cerebellar ataxia. Clin Genet 1970; 1:225-31.

20 Spira PJ, McLeod JG, Evans WA. A spinocerebellar degeneration with X-linked inheritance. Brain 1979; 102:27-41.

21 Fraser D. Defect of the cerebellum occurring in a brother and sister. Glasgow Med J 1880; 13: 199-210.

22 Nonne M. Uber eine eigenthümliche familiäre Erkrankungsform des Centralnervensystems. Arch Psychiat Nervenkr 1891; 22:283-316.

23 Marie $P$. Sur l'hérédoataxie cérébelleuse. Sem Med (Paris) 1893; 13:444-7.

24 Bell J, Carmichael EA. On hereditary ataxia and spastic paraplegia. Treasury of Human Inheritance, Vol IV, Part III. Cambridge: Cambridge University Press 1939; 141-281.

25 Hogan GR, Bauman ML. Familial spastic ataxia: occurrence in childhood. Neurol (Minneap) 1977; 27:520-6.

26 Hodge G. Three cases of Friedreich's disease all presenting marked increase of the knee jerk. $\mathrm{Br}$ Med J 1897; 1:1405-6.

27 Burgess. Friedreich's disease. $\mathrm{Br}$ Med J 1892; 1:768-9.

28 Soderburgh G. Un cas de maladie familiale. $R e v$ Neurol (Paris) 1910; 20:7-12.

29 Sinkler W. Friedreich's ataxia, with a report of thirteen cases. NY State J Med 1906; 83:65-72.

30 Harris W. Two cases of cerebellar ataxy. Proc $R$ Soc Med 1908; 1:52-4.

31 Fickler A. Klinische und pathologischanatomische Beiträge zu den Erkrankungen des Kleinhirns. Deutsche Ztschr Nervenh 1911; 41: 306-75.

32 Winkler C. A case of olivopontine cerebellar atrophy and our conceptions of neo- and palaiocerebellum. Schweiz Arch Neurol Psychiat 1923; 13:684-702

33 Bouchard JP, Barbeau A, Bouchard R, Bouchard RW. Autosomal recessive spastic ataxia of Charlevoix-Saguenay. Canad J Neurol Sci 1978; 5:61-9.

34 Cross HE, McKusick VA. The Troyer syndrome. A recessive form of spastic paraplegia with distal muscle wasting. Arch Neurol 1967; 16:473-85.

35 Langelier R, Bouchard JP, Bouchard R. Computed tomography of posterior fossa in hereditary ataxias. Canad J Neurol Sci 1979; 6:195-8. 